\title{
Lightweight Expanded Clay Aggregates (LECA), a New Up-scaleable Matrix for
}

\author{
Production of Microfungal Metabolites
}

\author{
Kristian Fog Nielsen*, Thomas Ostenfeld Larsen and Jens Christian Frisvad \\ Mycology Group, BioCentrum-DTU, Technical University of Denmark \\ Søltofts Plads, Building 221, DK-2800 Kgs. Lyngby, Denmark
}

(Received for publication September 1, 2003)

\begin{abstract}
In order to compare the effects of different growth matrices on secondary metabolite production we compared 16 Penicillium species known to produce several families of bioactive compounds. The isolates were grown in rich complex media formulated as semisolid (agar), liquid (still), shake culture, and absorbed in Lightweight Expanded Clay Aggregates (LECA). Both the number of metabolites and their quantities were compared via a chemo-diversity index. The matrix had a profound effect on fungal growth and secondary metabolism in some of the investigated species. LECA was shown to be a powerful alternative for production of sporulation-associated metabolites, such as cyclopenins and viridicatins, for quick up-scaling from agar based media, and as an alternative for production of metabolites that are not induced under submerse conditions.
\end{abstract}

Microfungi are rich sources of chemical diversity and are some of the most promising microbial sources for new bioactive metabolites as only a small part of the mycobiota is known ${ }^{1 \sim 4)}$. However, efficient drug discovery obviously also depends heavily on getting the microorganisms to express as much of their metabolic potential as possible ${ }^{5,6)}$. For studies on new fungal metabolites GLOER ${ }^{3)}$ strongly argues that solid state fermentations should be used as this is the matrix where fungi have evolved. This corresponds well to our findings from chemotaxonomic studies where solid substrates formulated as semi-synthetic agars, such as yeast extract sucrose (YES) ${ }^{7)}$, Czapek yeast autolysate (CYA), alkaloid forming agar (ALK) ${ }^{8)}$ were found to be superior to liquid cultures as long as very crude yeast extracts were used ${ }^{9,10)}$. From $100 \sim 200$ plates ( 3 point inoculated) we were able to isolate sufficient material (usually $2 \sim 50 \mathrm{mg}$ ) for structure determination of target metabolites ${ }^{11)}$. Although agar cultures gives a superior confirmation of the purity of the cultures, handling of many plates is laborious and poses safety problems. We therefore examined the feasibility of fermentations using the same media loaded into a porous inert support as done for production of various metabolites on polymers ${ }^{12,13)}$ and partially inert supports ${ }^{14,15)}$. A quick survey with various Penicillia and black Aspergilli on LECA, pimp stone and cat litter absorbent (moler) loaded $(\sim 20 \% \mathrm{v} / \mathrm{v})$ with YES, CYA and ALK, showed that much heavier sporulation occurred accompanied with slightly higher metabolite production. It was not necessary to add agar to get a good coating of the surface of the porous support without filling the main cavities in the particles. Moler was found to have the best loading capacity but also easily formed large closed particles leading to anaerobic conditions and therefore LECA was selected for further study. It is also the cheapest material, can be stacked to several meters height, is resistant to acids, bases and organic solvents, is free of organic impurities (produced at $1150^{\circ} \mathrm{C}$ ), and can be reused after reheating to the production temperature.

This paper presents a survey of the secondary metabolite profiles of 16 terverticillate Penicillia (12 species) and 7 biverticillate Penicillia (4 species) grown on YES and OAT media, respectively. Cultures were grown as LECA, semisolid agar, liquid and shake cultures.

* Corresponding author: kfn@biocentrum.dtu.dk 


\section{Materials and Methods}

\section{Chemicals, Media and Strains}

Water (aq) was Milli-Q treated. All chemicals were analytical grade, except solvents which were HPLC grade. LECA (not coated) was obtained from Dansk Leca A/S as a 10 to $20 \mathrm{~mm}$ fraction, with a dry bulk and a particle density of 210 and $390 \mathrm{~kg} / \mathrm{m}^{3}$ respectively. The LECA was washed with aq and dried at $100^{\circ} \mathrm{C}$ for 2 days. YES medium consisted of yeast extract (Difco, 212750) 2\%, sucrose $15 \%, \quad \mathrm{MgSO}_{4} \cdot 7 \mathrm{H}_{2} \mathrm{O} \quad 0.05 \%, \quad \mathrm{ZnSO}_{4} \cdot 7 \mathrm{H}_{2} \mathrm{O} \quad 0.001 \%$, $\mathrm{CuSO}_{4} \cdot 5 \mathrm{H}_{2} \mathrm{O} \quad 0.0005 \%$, aq to 1.0 liter, $\mathrm{pH}$ 6.5. OAT medium consisted of oat meal $3 \%, \mathrm{ZnSO}_{4} \cdot 7 \mathrm{H}_{2} \mathrm{O} 0.001 \%$, $\mathrm{CuSO}_{4} \cdot 5 \mathrm{H}_{2} \mathrm{O} 0.0005 \%$, aq to 1.0 liter, $\mathrm{pH}$ 6.0. YES and OAT-agars additionally contained $2 \%$ agar.

YEA and OAT were both prepared as (Fig. 1): i) agar, $4 \mathrm{ml}$ in a $50 \mathrm{ml}$ Blue Cap bottle; ii) liquid, $4 \mathrm{ml}$ in a $50 \mathrm{ml}$ Blue cap bottle; iii) shake, $8 \mathrm{ml}$ in a $25 \mathrm{ml}$ Blue Cap bottle; iv) LECA ( 8 particles) and $4 \mathrm{ml}$ media in a $50 \mathrm{ml}$ Blue cap bottle.

Fungal cultures (Table 1) were identified by micro and macro morphology, and metabolite profiling according to SAMSON et al. ${ }^{16)}$ and are available from the IBT Culture Collection (authors address). The agar cultures were inoculated in one spot, whereas the liquid, shake and LECA were inoculated with a $30-\mu \mathrm{l}$ spore suspension $(\sim 10,000$ spores $/ \mathrm{ml})$. The Blue caps were positioned loosely on top of the bottles without twisting. The shake cultures were kept at 140 rotations per minute. All inoculations were done in duplicates at $25^{\circ} \mathrm{C}$, and unless otherwise indicated, the cultures were extracted after 7 days. To test the influence of trace substances from the LECA, two batches of YES agar where prepared, one with pure water and one with water used to wash the same volume of LECA.

\section{Chemical Analyses}

The agar cultures were cut into small pieces $(2 \sim 3 \mathrm{~mm})$ with a scalpel prior to extraction. The culture bottles were extracted twice with $14 \mathrm{ml}$ EtOAc (first extraction over night, second extraction after 30 minutes of shaking), and the pooled EtOAc phases evaporated to dryness at $1 \mathrm{mbar}$, $1,300 \mathrm{rpm}$ at $35^{\circ} \mathrm{C}$ in a rotational vacuum concentrator. The residues were dissolved in $1.0 \mathrm{ml}$ methanol, ultrasonicated for 10 minutes, and filtered through $0.45 \mu$ PTFE syringe filters.

Samples of $3 \mu 1$ were injected on an Agilent 1100 Liquid Chromatographic system equipped with a diode array (DAD) and a fluorescence detector (FLD). The system was equipped with a BDS- $\mathrm{C}_{18}$ column ( $3 \mu \mathrm{m}$ particles, $125 \mathrm{~mm}$ long), and separation was achieved by a water-acetonitrile $(\mathrm{AcN})$ gradient (both containing $0.0050 \%$ TFA), going from 15 to $100 \% \mathrm{AcN}$ in 40 minutes and then 3 minutes isocratic ${ }^{17}$. Ergosterol was quantified by external standard calibration.

\section{Data Analysis}

The LC-DAD data files were inspected at 202, 210, 250, $280 \mathrm{~nm}$ and compared with whole UV spectra of known metabolites of the species investigated. Peaks $\geq 10$ mAu $\times$ second for the terverticillate penicillia and $\geq 1$ $\mathrm{mAu} \times$ second $\mathrm{mAu}$ for the biverticillate penicillia (excluding those found in blank samples) were matched against the Mycology Group reference-standard database $(\sim 550 \text { compounds })^{18)}$. Major peaks not available as reference standards were tentatively identified by LC-DADESI $^{+}$-HR-MS ${ }^{18}$.

A chemo-diversity index (CDI), introduced here, was defined as the sum of the $\log _{10}$ of all peaks $(\mathrm{N})$ (ergosterol was excluded) having a peak area, at their UV max, greater than a peak threshold $(\mathrm{t})$ :

$$
\mathrm{CDI}=\sum_{n=1}^{\text {Narea } \geq 1} \log _{10}(\text { ara })
$$

\section{Results and Discussion}

\section{Fungal Growth}

Visual observations (Fig. 1) clearly showed that significant more sporulation occurred on the LECA compared with the other formulations. Since there were no visual indications of more biomass production on LECA, the proportion of the biomass being spores must have been very high as the ergosterol quantities were much higher.

To test, if the differences observed between the formulations were not a result of the chosen time of extraction ( 7 days), one of the species with the largest difference in produced biomass and metabolites, $P$. aurantiocandidum, was subjected to a time course study as seen in Figs. 2 and 3. The results showed that the incubation time had no significant effects on the higher ergosterol and subsequent biomass production on LECA versus the other formulations. The declining levels of ergosterol after 11 days for agar and liquid could be due to degradation and/or esterification. Figs. 2 and 3 shows that the CDI on the different formulations were stable after one week, and that the differences in metabolite productions were not a result of cultures in different growth stages. 
Fig. 1. Penicillium venetum, IBT 23040 on YES, formulated as (from left): shake, liquid, agar and LECA media.

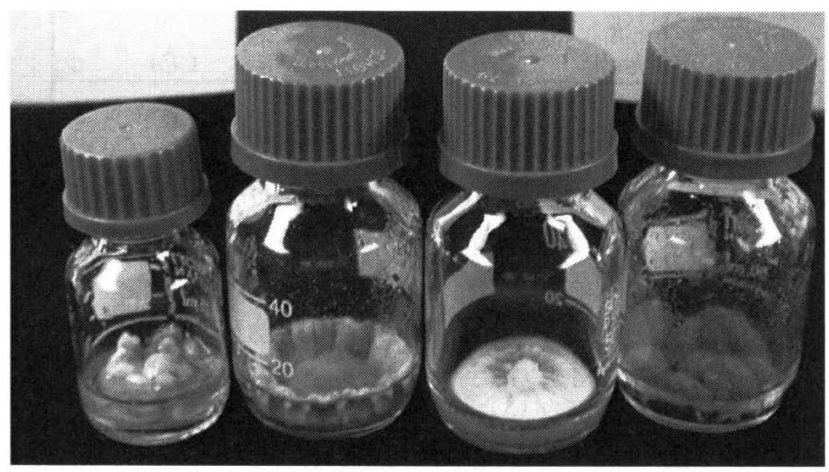

Pellets are clearly seen in the shake culture. Sporulation is seen as the dark areas on liquid, LECA and parts of centre of the agar culture.

Fungal Metabolism

Terverticiliate Penicillia

Data in Table 1, and Figs. 4 and 5, showed that still liquid cultures gave the highest CDI, but that LECA gave more peaks at low peak threshold values $<20 \mathrm{mAu} \times$ s (Fig. 5). As seen in Figs. 4 and 5 shake conditions were profoundly different from the three other conditions presumably as a result of pellet production.

Table 1 also shows that some species prefers shaking while others prefers solid media. While $P$ allii and $P$. carneum produced most metabolites in shake cultures, $P$. solitum, $P$. cyclopium, $P$. aurantigriseum, $P$. aurantiocandidum, and $P$ venetum gave very poor metabolite production when shaken compared to solid cultures. These results clearly show that it is worthwhile to investigate the matrix effects during screening of fungal cultures.

Terrestric acid (produced by $P$. aurantiogriseum, $P$. venetum, $P$. hirsutum, $P$. hordei, and $P$. radicicola) was a predominant product under some culture conditions. It accounted for 75 and $95 \%$ of the total peak area in shake cultures of $P$. hirsutum and $P$. hordei respectively compared with $18 \%$ and $75 \%$ on LECA, illustrating why it is necessary to rate the quantity of individual metabolites against the number of metabolites in a non-linear way.

P. solitum sporulated extremely well on the LECA, and as seen in Table 2, this resulted in high production of
Fig. 2. Production of biomass measured as ergosterol as function of time of $P$. aurantiocandidum (IBT 3514) incubated on yeast extract sucrose medium formulated in LECA, as agar, liquid (still) and shake culture.

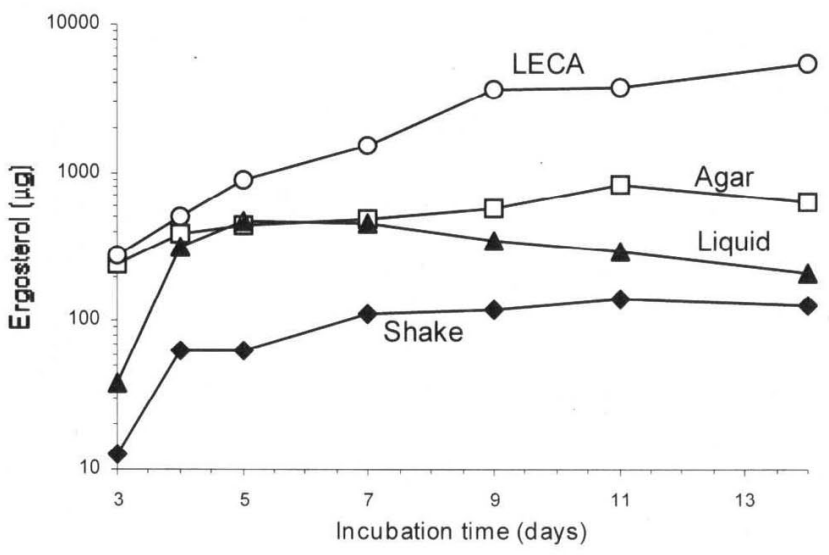

Fig. 3. The CDI as function of time of $P$. aurantiocandidum (IBT 3514) incubated on yeast extract sucrose medium formulated in LECA, as agar, liquid (still) and shake culture.

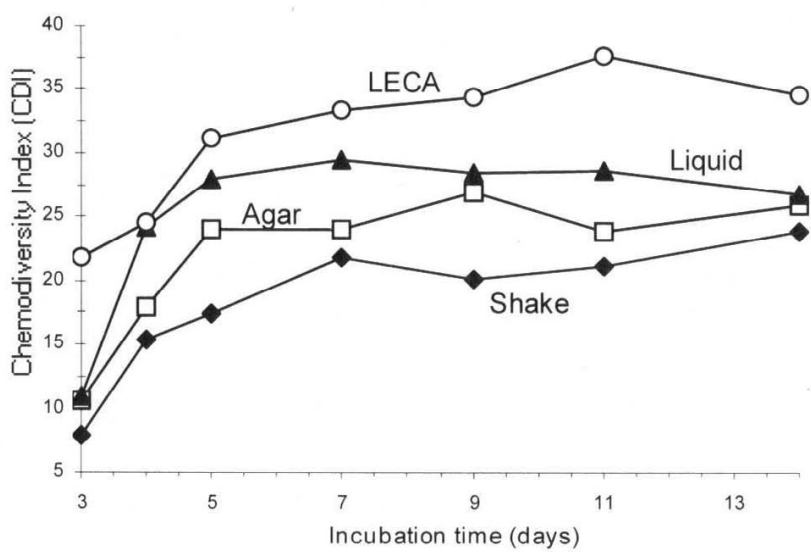

cyclopenol and cyclopenin $(60 \sim 70 \%$ of total peak area), components known to protect the spores ${ }^{19)}$. The boosting of these metabolites is presumable the reason for the suppression of the production of non-sporulation associated metabolites. Thus if these metabolites are desired LECA is the choice of matrix. However, if compactins are the targets using $P$. solitum, shake conditions should be used, as the large contents of viridicatol and cyclopenol analogues makes it more difficult to isolate the compactins. The same 
Table 1. Number of peaks, chemo diversity index ${ }^{1}$ and ergosterol quantity detected from the cultures grown on $\mathrm{YES}^{2}$ or OAT media formulated in LECA, as semisolid agar, as liquid and shake media.

\begin{tabular}{|c|c|c|c|c|c|c|c|c|c|c|c|c|c|}
\hline Species & $\begin{array}{l}\text { IBT } \\
\text { no. }^{3}\end{array}$ & $\begin{array}{c}\# \\
\text { peaks }\end{array}$ & $\begin{array}{l}\text { Leca } \\
\mathrm{CDI}^{1}\end{array}$ & $\begin{array}{c}\mathrm{Erg} \\
\mu \mathrm{g}\end{array}$ & $\begin{array}{c}\# \\
\text { peaks }\end{array}$ & $\begin{array}{l}\text { Agar } \\
\text { CDI }\end{array}$ & $\begin{array}{r}\mathrm{Erg} \\
\mu \mathrm{g}\end{array}$ & $\begin{array}{c}\# \\
\text { peaks }\end{array}$ & $\begin{array}{l}\text { Liquid } \\
\text { CDI }\end{array}$ & $\begin{array}{l}\mathrm{Erg} \\
\mu \mathrm{g}\end{array}$ & $\begin{array}{c}\# \\
\text { peaks }\end{array}$ & $\begin{array}{r}\text { Shake } \\
\text { CDI }\end{array}$ & Erg \\
\hline \multicolumn{14}{|l|}{ terverticillate penicillia } \\
\hline P. solitum & 21838 & 19 & 45.7 & 87 & 25 & 52.2 & 90 & 20 & 49.8 & 69 & 9 & 13.5 & ND \\
\hline P. solitum & 21545 & 20 & 41.4 & 86 & 23 & 46.4 & 89 & 23 & 49.1 & 140 & 7 & 10.4 & 7.6 \\
\hline P. cyclopium & 21519 & 19 & 47.8 & 401 & 19 & 42.8 & 192 & 16 & 36.2 & 140 & 8 & 14.1 & 23 \\
\hline P. carneum & 19478 & 24 & 46.6 & 151 & 25 & 61.4 & 307 & 26 & 62.3 & 255 & 24 & 58.2 & 185 \\
\hline P. carneum & 6880 & 28 & 53.3 & 158 & 30 & 69.2 & 426 & 30 & 68.2 & 330 & 28 & 69.2 & 166 \\
\hline P. aethiopicum & 21501 & 11 & 32.3 & 309 & 11 & 35.3 & 561 & 11 & 35.0 & 646 & 11 & 33.9 & 270 \\
\hline P. aethiopicum & 16873 & 17 & 43.1 & 233 & 19 & 52.4 & 299 & 20 & 57.7 & 739 & 20 & 52.7 & 369 \\
\hline P. aurantiocandidum & 3514 & 14 & 40.4 & 1426 & 11 & 25.9 & 485 & 12 & 31.6 & 461 & 13 & 30.7 & 286 \\
\hline$P$. aurantiogriseum & 14016 & 12 & 24.9 & 542 & 8 & 14.7 & 138 & 9 & 20.9 & 159 & 3 & 5.1 & 8.8 \\
\hline P. aurantiogriseum & 15986 & 29 & 67.0 & 352 & 17 & 32.5 & 168 & 8 & 19.0 & 127 & 8 & 18.0 & 70 \\
\hline$P$. venetum & 23040 & 35 & 81.8 & 457 & 36 & 72.8 & 37 & 38 & 86.5 & 171 & 26 & 57.0 & ND \\
\hline P. albocoremium & 10682 & 23 & 52.6 & 115 & 25 & 64.1 & 43 & 22 & 63.1 & 27 & 22 & 59.5 & 72 \\
\hline P. hirsutum & 13033 & 27 & 61.6 & 202 & 29 & 69.7 & 109 & 29 & 79.6 & 36 & 28 & 69.7 & 25 \\
\hline P. hordei & 4154 & 18 & 42.6 & 457 & 15 & 31.8 & 73 & 15 & 33.3 & 133 & 16 & 39.1 & 31 \\
\hline P. radicicola & 10696 & 19 & 47.5 & 479 & 7 & 16.5 & 77 & 20 & 54.2 & 228 & 13 & 36.3 & 96 \\
\hline P. allii & 3772 & 16 & 34.2 & 330 & 19 & 44.7 & 226 & 16 & 33.4 & 139 & 19 & 53.0 & 809 \\
\hline Average & & 20.7 & 47.7 & 362 & 19.9 & 45.8 & 208 & 19.7 & 48.7 & 237 & 15.9 & 38.8 & 161 \\
\hline \multicolumn{14}{|l|}{ biverticillate penicillia } \\
\hline P. minioluteum & 21713 & 15 & 25.8 & 24 & 14 & 20.8 & 24 & 13 & 18.0 & 5.0 & 20 & 35.7 & 5.0 \\
\hline P. minioluteum & 22947 & 10 & 21.0 & 2.1 & 10 & 17.2 & 0.6 & 11 & 24.5 & ND & 10 & 14.6 & ND \\
\hline P. primulinum & 3805 & 7 & 5.0 & ND & 10 & 12.0 & $\mathrm{ND}$ & 10 & 18.7 & 10 & 8 & 11.5 & 2.5 \\
\hline P. aculeatum & 23694 & 23 & 39.6 & 32 & 21 & 33.5 & 25 & 21 & 41.8 & 49 & 23 & 37.7 & 33 \\
\hline P. aculeatum & 14262 & 23 & 44.6 & 63 & 23 & 33.3 & 42 & 23 & 41.5 & 28 & 21 & 39.3 & 16 \\
\hline P. dendriticum & 10636 & 12 & 18.8 & 89 & 9 & 11.8 & 3.2 & 12 & 19.7 & 111 & 13 & 20.5 & 44 \\
\hline P. dendriticum & 23690 & 18 & 34.4 & 13 & 10 & 15.4 & 5.0 & 21 & 48.8 & 24 & 20 & 30.4 & 2.5 \\
\hline Average & & 15.4 & 27.0 & 37 & 13.9 & 20.6 & 17 & 15.9 & 30.4 & 38 & 16.4 & 27.1 & 17 \\
\hline
\end{tabular}

${ }^{1}$ Chemo diversity index, at a threshold of $10 \mathrm{mAu} \times \mathrm{sec}$ for the terverticillate Penicillia and $1 \mathrm{mAu} \times \mathrm{sec}$ for the biverticillate

Penicillia. ${ }^{2}$ See Materials and Methods for media recipes. ${ }^{3}$ IBT Culture Collection.

boosting of cyclopenol, cyclopenin and viridicatol by LECA was also observed in P. cyclopium as illustrated in Fig. 6.

Table 2 also shows that if $P$. carneum is to be used for production of mycophenolic acid(s) shake culture is preferable, since the mycotoxin, patulin was not produced in detectable quantities $(<2 \sim 10 \mu \mathrm{g})$ under these conditions. Conversely the mycotoxin penicillic acid was not produced $(<2 \sim 10 \mu \mathrm{g})$ by P. cyclopium on LECA, illustrating that the matrix can also be used to manipulate production of undesired metabolites.

Comparison of the YES agars (triplicates) prepared from pure water and water previous used to wash the same volume LECA showed no differences in growth and metabolite production for $P$. aurantiocandidum, $P$. carneum, and $P$. aethiopicum, showing that it was not trace elements from the LECA that induced the heavy sporulation.

\section{Biverticillate Penicillia}

The CDI (Fig. 7) and number of peaks (Fig. 8) for the biverticillate Penicillia investigated were highest in liquid culture and similar for the shake and LECA formulations. The low metabolite production on agar could be a result of significant lower biomass production, as less than half the quantities of ergosterol were detected compared with liquid media. On the other hand the terverticillate Penicillia produced only $13 \%$ less ergosterol on agar compared with liquid media. However, the most profound difference 
Fig. 4. Comparison of the average chemodiversity index (CDI) as function of the minimal peak area from the studied terverticillate penicillia grown on yeast extract sucrose medium formulated in LECA, as liquid, shake and agar media.

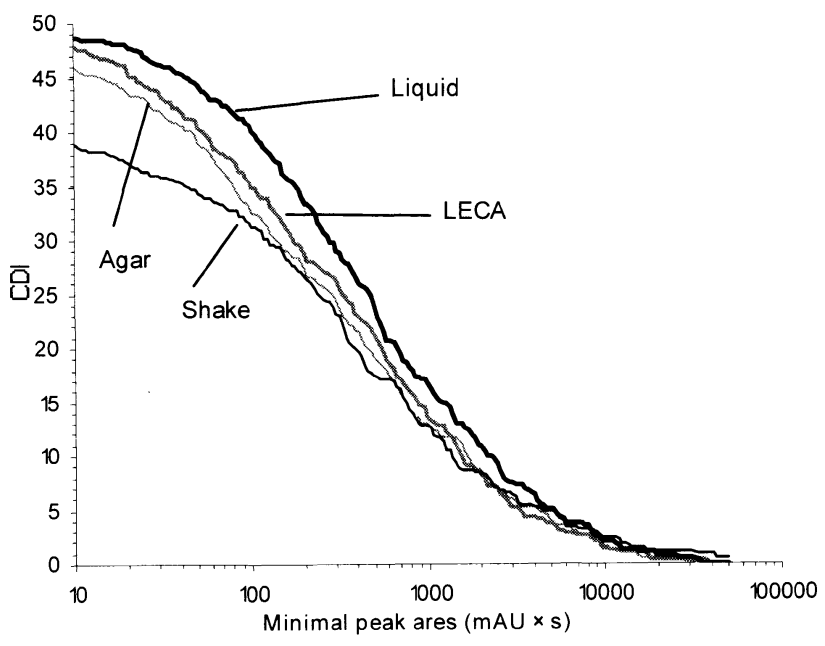

Fig. 5. Comparison of the average number of metabolite as function of the minimal peak area from the studied terverticillate penicillia grown on yeast extract sucrose medium formulated in LECA, as liquid, shake and agar media.

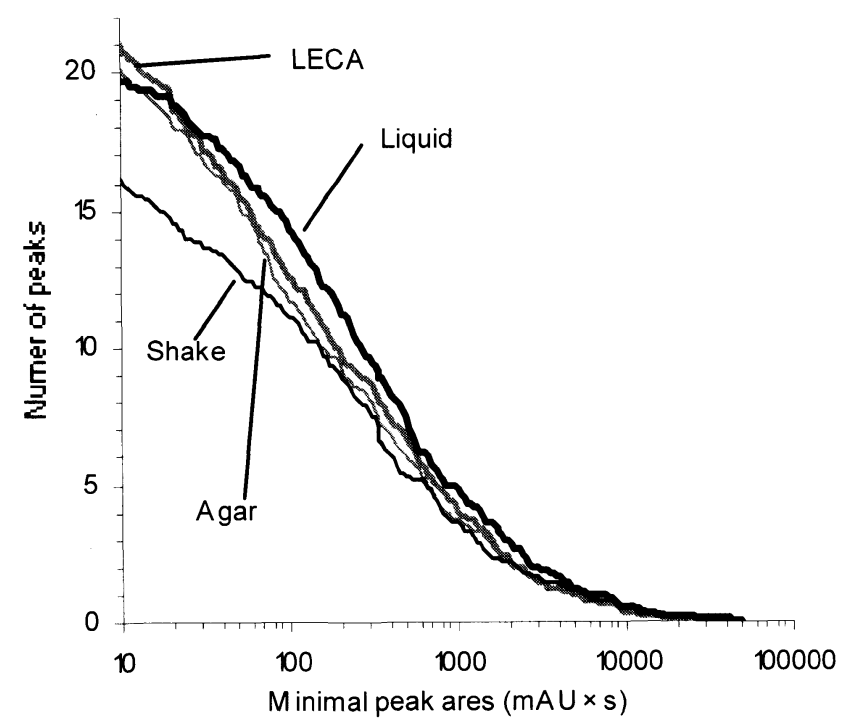

Table 2. Area ratios of selected bioactive metabolites, the number metabolites related to them and their overall ratio compared with other metabolites from YES cultures media formulated in LECA, as semisolid agar, as liquid and shake media.

\begin{tabular}{|c|c|c|c|c|c|c|c|c|c|c|c|c|c|c|}
\hline Species & IBT no. & Target & $\begin{array}{c}\text { Area } \\
\%\end{array}$ & $\begin{array}{l}\text { Leca } \\
\text { Analo } \\
\text { gues* }\end{array}$ & $\begin{array}{l}\text { Total } \\
\% \star \star\end{array}$ & $\begin{array}{c}\text { Area } \\
\%\end{array}$ & $\begin{array}{c}\text { Agar } \\
\text { Analo } \\
\text { gues }\end{array}$ & $\begin{array}{c}\text { Total } \\
\% \\
\end{array}$ & $\begin{array}{c}\text { Area } \\
\% \\
\end{array}$ & $\begin{array}{l}\text { Liquid } \\
\text { Analo } \\
\text { gues }\end{array}$ & $\begin{array}{c}\text { Total } \\
\% \\
\end{array}$ & $\begin{array}{c}\text { Area } \\
\% \\
\end{array}$ & $\begin{array}{c}\text { Shake } \\
\text { Analo } \\
\text { gues }\end{array}$ & $\begin{array}{c}\text { Total } \\
\% \\
\end{array}$ \\
\hline P. solitum & 21838 & Compactin $^{1}$ & 0.2 & 3 & 4 & 23 & 3 & 26 & 17 & 3 & 30 & 2 & 3 & 14 \\
\hline P. solitum & 21545 & Compactin $^{1}$ & 2 & 3 & 5 & 24 & 3 & 13 & 21 & 3 & 20 & 2 & 3 & 8 \\
\hline P. solitum & 21838 & Viridicatin $^{2}$ & 0.2 & 3 & 90 & 4.1 & 2 & 7 & 8.1 & 2 & 17 & 0.2 & 1 & 9 \\
\hline P. solitum & 21545 & Viridicatin $^{2}$ & 0.3 & 4 & 84 & ND & 4 & 14 & 1.5 & 4 & 11 & ND & ND & \\
\hline P. cyclopium & 21519 & $\begin{array}{l}\text { 3-methoxy- } \\
\text { viridicatin }\end{array}$ & 0.3 & 3 & 42 & 0.6 & 3 & 22 & ND & 1 & 3 & 0.1 & 1 & 2 \\
\hline P. cyclopium & 21519 & Penicillic acid & ND & & & 36 & & & 66 & & & 49 & & \\
\hline P. carneum & 19478 & Mycophenolic acid ${ }^{4}$ & 14 & 8 & 13 & 13 & 9 & 19 & 25 & 10 & 20 & 30 & 10 & 26 \\
\hline P. carneum & 6880 & Mycophenolic acid ${ }^{4}$ & 11 & 11 & 13 & 17 & 11 & 18 & 26 & 12 & 15 & 28 & 12 & 28 \\
\hline P. carneum & 19478 & Patulin & 11 & & & 27 & & & 17 & & & ND & & \\
\hline P. carneum & 6880 & Patulin & 8 & & & 24 & & & 22 & & & ND & & \\
\hline P. aethiopicum & 21501 & Griseofulvin $^{5}$ & 21 & 1 & 3 & 25 & 1 & 7 & 24 & 1 & 9 & 21 & 1 & 10 \\
\hline P. aethiopicum & 16873 & Griseofulvin $^{5}$ & 14 & 5 & 16 & 16 & 4 & 12 & 11 & 5 & 13 & 5 & 5 & 5 \\
\hline $\begin{array}{l}P \text {. aurantio- } \\
\text { candidum }\end{array}$ & 3514 & $\begin{array}{l}\text { 3-methoxy- } \\
\text { viridicatin }\end{array}$ & 3 & 1 & 8 & 0.0 & 1 & 0.7 & ND & ND & & ND & ND & \\
\hline
\end{tabular}

ND not detected. ${ }^{\star}$ Number of analogues and precursors detected. ${ }^{\star \star} A$ rea $\%$ of all the analogues and precursors detected. ${ }^{1}$ Compactin, ML-236A and ML-236C. ${ }^{2}$ viridicatin, cyclopenol, cyclopenin, cyclopeptin, and dehydrocyclopeptin. ${ }^{3}$ viridicatol, viridicatin, cyclopenol cyclopenin, cyclopeptin, and dehydrocyclopeptin. ${ }^{4}$ Including all metabolites with similar UV spectra. ${ }^{5}$ Dechlorogriseofulvin, epi-dechlorogrisofulvin, and xanthones. 
Fig. 6. Chromatograms $(200 \sim 600 \mathrm{~nm})$ from extracts of Penicillium cyclopium IBT 21519, grown on YES formulated in LECA and as shake culture.

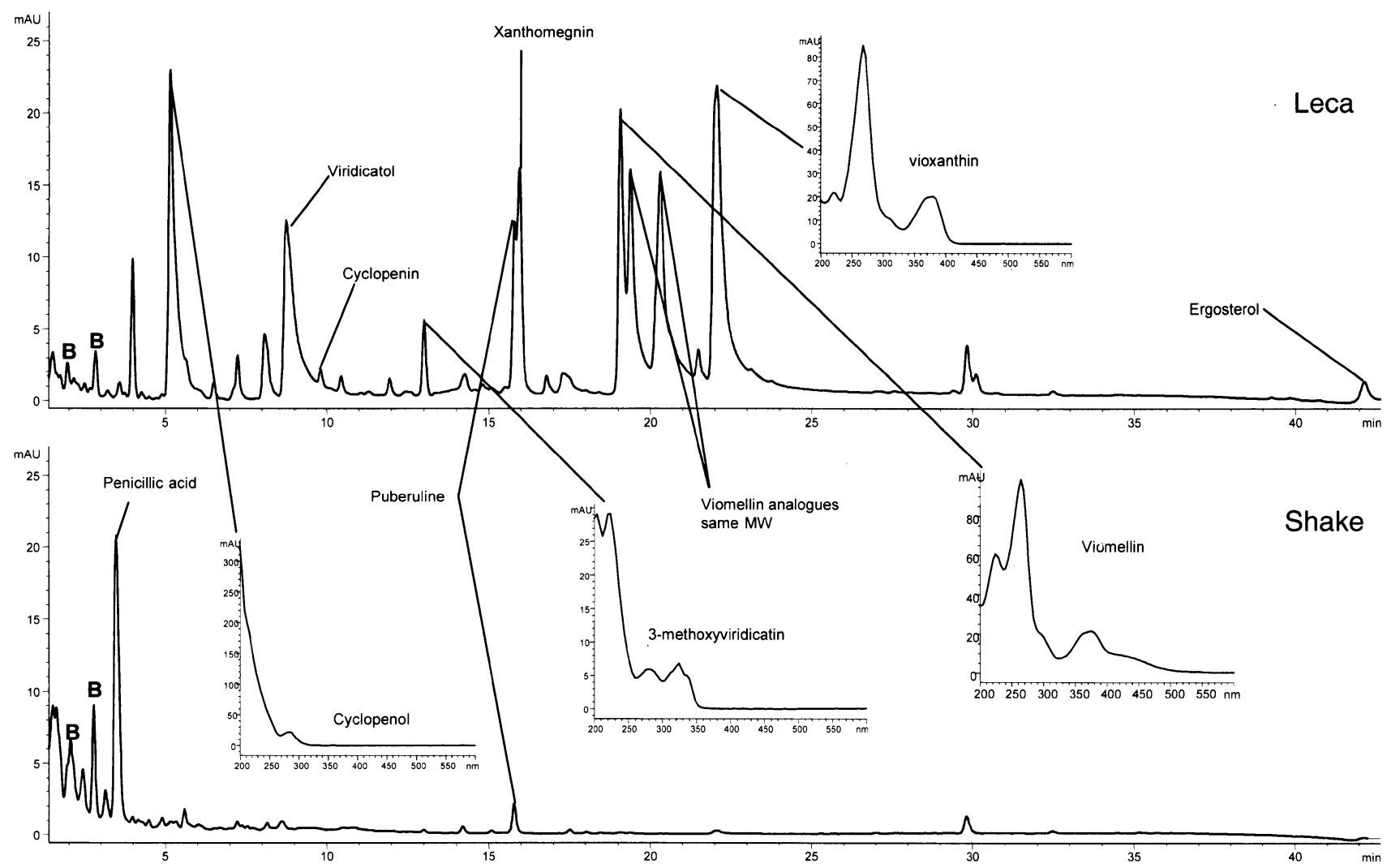

B: component from growth media.

Fig. 7. Comparison of the average chemodiversity index (CDI) as function of the minimal peak from the studied biverticillate penicillia grown on oat meal medium formulated in LECA and as liquid, shake and agar media.

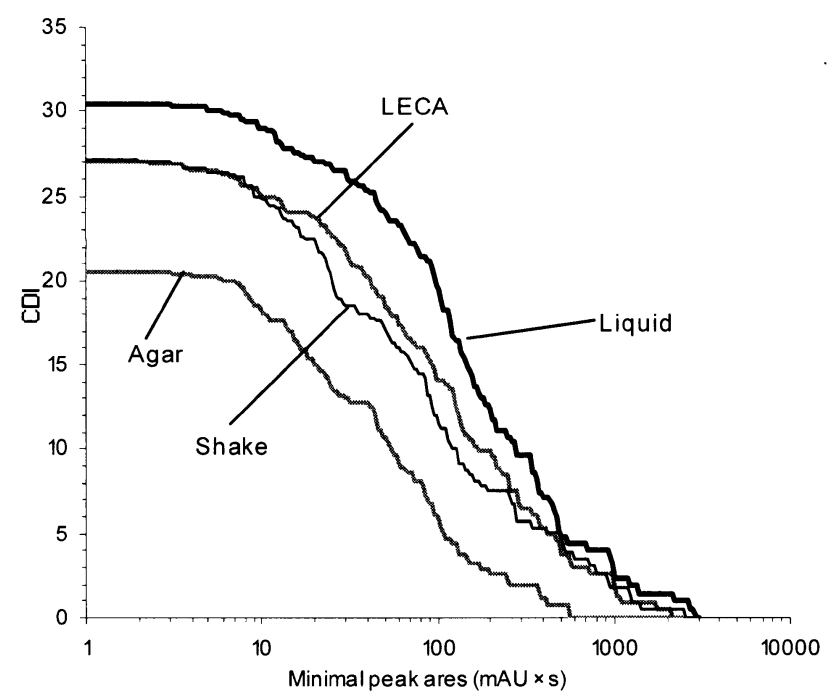

Fig. 8. Comparison of the average number of metabolite as function of the minimal peak area from the studied biverticillate penicillia grown on oat meal medium formulated in LECA and as liquid, shake and agar media.

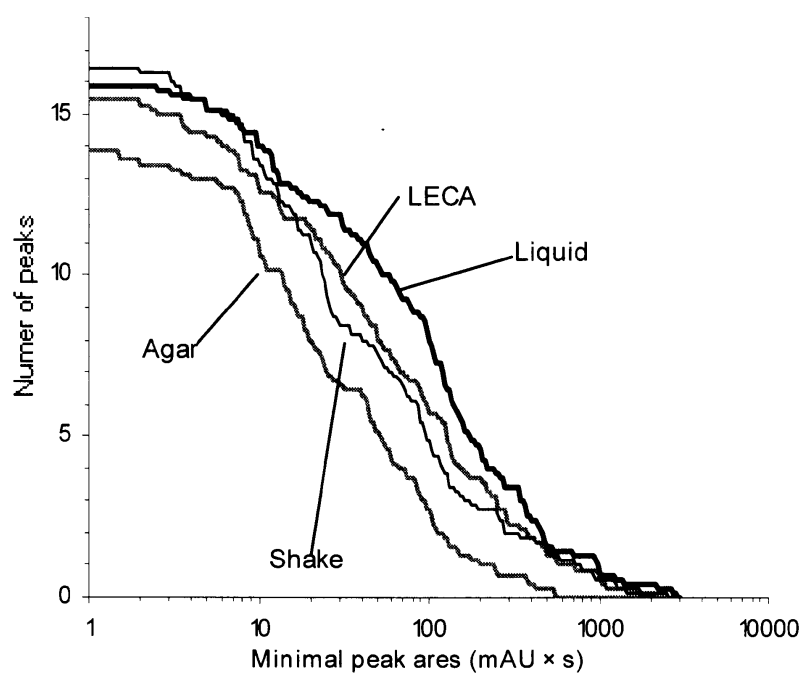


compared with LECA was slightly higher quantities of all metabolites in the liquid medium rather than changes in the profile. This may be due to the high viscosity of the OAT medium, so it covers the pores in the LECA.

\section{Overall Discussion}

HigGS et al. ${ }^{5)}$ used a productivity index calculated on direct-infusion-ESI MS spectra to measure chemical diversity, where the quantities of the individual metabolites were rated linear until a certain threshold. We chose to logarithmize the peak areas, as it has been commonly employed in multivariate statistical analyses ${ }^{20)}$. Both indices assess the number of metabolites above a certain threshold to assure that isolates producing a high number of metabolites in low quantitative are not favoured over isolates producing many metabolites in high quantities. Both indices can easily be plotted as function of a minimal quantity to determine the distribution of the peak quantities, e.g. as a MS spectrum ${ }^{5}$ or as those shown in Figs. 4, 5, 7 and 8. It should be noted that our CDI is biased by showing UV absorbing components only. An evaporative light scattering detector would have given a more universal picture ${ }^{5)}$ of metabolite production by the cultures. However such a detector was not available to us. LC-ESI-MS could have been employed to detect more metabolites but such results are even more biased towards large ionisable metabolites ${ }^{18)}$.

Comparing the analytical results from agar versus the other formulations, no unique metabolites were found compared with previous studies in our lab. Thus agar cultures are still preferable for screening because of the easy handling of agar cultures and the confirmation of the purity of the cultures.

It is our opinion that on such a rich and complex medium as YES there is very little if any regulation of the secondary metabolism, which is supported by observations showing that very crude yeast extract gives better metabolite production $^{9,10)}$. Therefore one should be careful to extrapolate these results to simple and defined media where the metabolism is controlled strictly ${ }^{3,21)}$.

The positive effect of LECA on the production of some metabolites as well as sporulation is not surprising as micro-fungi generally have evolved on solid media compared with yeast and bacteria which are more suited to grow in liquid media ${ }^{22)}$. Whether this effect on sporulation is due to the solid matrix itself or to the faster local depletion of nutrients, as the medium is only found as a thin film on the walls of the porous LECA particles, cannot be determined from these experiments.

All together LECA is an interesting alternative to other media formulations for the production of sporulation associated metabolites, for convenient scale up of production of up to $100 \sim 200 \mathrm{mg}$ quantities for in vivo studies, and for the isolation of metabolites not being produced under submerse conditions. For scaling up operations (results not shown), we have found 5-liter bottles with 4.5 liters LECA can be easily handled. About $900 \sim 1000 \mathrm{ml}$ YES or CYA medium (corresponding to the contents of $45 \sim 50$ Petri dishes) can be absorbed on the LECA during autoclaving, although it may be necessary to rotate the bottle $30 \sim 60$ seconds afterwards to get the last $5 \sim 15 \%$ medium absorbed and evenly distributed. Under such conditions uniform growth in the whole bottle without mechanical aeration have been observed. Compared with the polymer based supports ${ }^{12,13,23)}$ LECA has the advantage that it can be extracted with organic solvents.

For industrial gram scale production of metabolites using LECA a new bio-reactor design will be needed to cope with: i) uniform loading of the aggregates in the whole reactor; ii) aeration; iii) in-reactor extraction; iv) recycling of LECA for reuse.

\section{Acknowledgements}

This project was supported by the Danish Technical Research Council under the project "Functional biodiversity in Penicillium and Aspergillus" (grant no. 9901295). LISETTE KNOTH-NIELSEN is acknowledged for her for technical assistance for preparing media, inoculating fungi, extracting the cultures, and running the HPLC analyses.

\section{References}

1) Cordell, G. A. \& Y. G. Shin: Finding the needle in the haystack. The dereplication of natural products extracts. Pure Appl. Chem. 71: 1089 1094, 1999

2) Eldridge, G. R.; H. C. Vervoort, C. M. Lee, P. A. Cremin, C. T. Williams, S. M. Hart, M. G. Goering, M. O'NeIL-JohnSON \& L. ZENG: High-throughput method for the production and analysis of large natural product libraries for drug discovery. Anal. Chem. 74: 3963 3971, 2002

3) Gloer, J. B.: The chemistry of fungal antagonism and defense. Can. J. Bot. 73: S1265 S1274, 1995

4) Bull, A. T.; A. C. WARd \& M. Goodfellow: Search and discovery strategies for biotechnology: the paradigm shift. Microbiol. Molec. Biol. Rev. 64: 573 606, 2002

5) Higgs, R. E.; J. A. Zahn, J. D. Gygu \& M. D. Hilton: Rapid method to estimate the presence of secondary metabolites in microbial extracts. Appl. Environ. Microbiol. 67: 371 376, 2001

6) Monaghan, R. L.; J. D. Polishook, V. J. Pecore, G. F. Bills, M. Nallin-Omstead \& S. L. Streicher: Discovery of novel secondary metabolites from fungiIs it really a random walk through a random forest? Can. J. Bot. 73: s925 s931, 1995

7) Frisvad, J. C.: Physiological criteria and mycotoxin 
production as aids in identification of common asymmetric penicillia. Appl. Environ. Microbiol. 41: 568 579, 1981

8) Reshetilova, T. A.; T. F. Solovyeva, B. P. Baskunov \& A. G. KOZLOVSKII: Investigation of alkaloid formation by certain species of fungi of the Penicillium genus. Mikrobiologiya 61: 873 879, 1992

9) Filtenborg, O.; J. C. Frisvad \& U. Thrane: The significance of yeast extract composition on metabolite production in Penicillium. In Modern Concepts in Penicillium and Aspergillus Classification, Eds., R. A. SAmson, J. I. Pitt, Plenum Press, New York, 1990

10) Frisvad, J. C. \& O. FiltenborG: Classification of terverticillate Penicillia based on profile of mycotoxins and other secondary metabolites. Appl. Environ. Microbiol. 46: 1301 1310, 1983

11) Larsen, T. O. \& J. Breinholt: Dichlorodiaportin, diaportinol, and diaportinic acid: Three novel isocoumarins from Penicillium nalgiovense. J. Nat. Prod. 62: 1182 1184, 1999

12) Tomasini, A.; C. Fajardo \& J. Barrios-Gonzalez: Gibberellic acid production using different solid-state fermentation systems. World J. Microbiol. Biotechnol. 13: 203 206, 1997

13) Gelmi, C.; R. Perez-Correa \& E. Agosin: Moddeling Gibberella fujikuroi growth and GA3 production in solid-state fermentations. Process Biochem. 37: 1033 1040, 2002

14) Sadhukhan, A. K.; M. V. R. Murthy, A. Kumar, E. V. S. Mohan, G. VAndana, C. Bhar \& K. V. RaO: Optimization of mycophenolic acid production in solid state fermentation using response surface methodology. J. Ind. Microbiol. Biotechnol. 22: 33 38, 1999
15) Dominguez, M.; A. Mejia, S. Revah \& J. BarriosGONZALEZ: Optimization of bagasse, nutrients and initial moistrure rations on the yield of penicillin in solidstate fermentations. World J. Microbiol. Biotechnol. 17: 751 756, 2001

16) Samson, R. A.; E. S. Hoekstra, J. C. Frisvad \& O. FiLTENBORG: Introduction to Food- and Air Borne Fungi. 6th Ed., Centraalbureau voor Schimmelcultures: Utrecht, 2002

17) SmedsgaARd, J.: Micro-scale extraction procedure for standardized screening of fungal metabolite production in cultures. J. Chromatogr. A 760: 264 270, 1997

18) Nielsen, K. F. \& J. SmedsgaArd: Fungal metabolite screening: Database of 474 mycotoxins and fungal metabolites for de-replication by standardised liquid chromatography-UV detection-mass spectrometry methodology. J. Chromatogr. A 1002: 111 136, 2003

19) Luckner, M.: Alkaloid biosynthesis in Penicillim cyclopium - Does it reflect general features of secondary metabolism. J. Nat. Prod. 43: 21 40, 1980

20) Blomquist, G.; E. Johansson \& B. Söderström: Data analyis of pyrolysis-chromatograms by means of SIMCA pattern recognition. J. Anal. Appl. Pyrol. 1: 53 65, 1979

21) Sanchez, S. \& A. L. Demain: Review: Metabolic regulation of fermentation processes. Enzyme Microb. Tech. 31: 895 906, 2002

22) Hesseltine, C. W.: A Microbe's view of fermentation. J. Ind. Microbiol. Biotechnol. 22: 482 499, 1999

23) Sabu, A.; T. R. Keerthi, S. R. Kumar \& M. CHANDRASEKARAN: L-Glutaminase production by marine Beauveria sp under solid state fermentation. Process Biochem. 35: 705 710, 2000 